\title{
Consensus statement on diagnosis, treatment and follow-up of cow's milk protein allergy among infants and children in Turkey
}

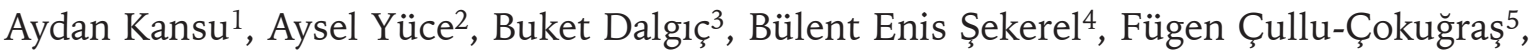 \\ Haluk Çokuğraş ${ }^{6}$ \\ ${ }^{1}$ Division of Pediatric Gastroenterology, Department of Pediatrics, Ankara University Faculty of Medicine, Ankara, ${ }^{2}$ Division \\ of Pediatric Gastroenterology, Department of Pediatrics, Hacettepe University Faculty of Medicine, Ankara, ${ }^{3}$ Division of \\ Pediatric Gastroenterology, Department of Pediatrics, Gazi University Faculty of Medicine, Ankara, ${ }^{4}$ Division of Pediatric \\ Allergy and Asthma, Department of Pediatrics, Hacettepe University Faculty of Medicine, Ankara, ${ }^{5}$ Division of Pediatric \\ Gastroenterology, Department of Pediatrics, Istanbul University Cerrahpasa Faculty of Medicine, Istanbul, ${ }^{6}$ Division of \\ Pediatric Allergy, Department of Pediatrics, Istanbul University Cerrahpasa Faculty of Medicine, Istanbul, Turkey. \\ E-mail: aydankansu@gmail.com \\ Received: 21 April 2016, Revised: 23 May 2016, Accepted: 11 July 2016
}

SUMMARY: Kansu A, Yüce A, Dalgıç B, Şekerel BE, Çullu-Çokuğraş F, Çokuğraş H. Consensus statement on diagnosis, treatment and follow-up of cow's milk protein allergy among infants and children in Turkey. Turk J Pediatr 2016; 58: 1-11.

The present paper aims to provide experts' consensus on diagnosis and management of cow's milk protein allergy (CMPA) among infants and children in Turkey, based on review of available evidence-based guidelines, publications and experts' clinical experience. The experts agreed that CMPA diagnosis should be based on symptomatic evaluation and diagnostic elimination diet as followed by implementation of an open challenge test after disappearance of symptoms and confirmation of CMPA diagnosis in re-appearance of symptoms. For breastfed infants, differential diagnosis involves withdrawal of cow's milk-containing products from the mother's diet, while calcium supplements and appropriate dietary advice are given to mothers to prevent nutritional deficiency. For infants not breastfed exclusively, cow's milk-based formula and any complementary food containing cow's milk protein (CMP) should be avoided. The first line treatment should be extensively hydrolyzed formula (eHF) with use of amino acid-based formula (AAF) in severe cases such as anaphylaxis, enteropathy, eosinophilic esophagitis and food protein induced enterocolitis along with cases of multiple system involvement, multiple food allergies and intolerance to eHF. Introduction of supplementary foods should not be delayed in CMPA, while should be made one by one in small amounts and only after the infant is at least 17 weeks of age. Infants who are at-risk can be identified by family history of atopic disease. Exclusive breastfeeding for 4-6 months (17-27 weeks) is recommended as the best method of infant allergy prevention. There is no evidence that modifying the mother's diet during pregnancy and/or breast-feeding and delaying solid or even potentially allergic foods beyond 4-6 months in infants may be protective against allergy among at-risk infants. When exclusive breastfeeding is not possible, at-risk infants should get a partially or extensively hydrolyzed formula (pHF or eHF) to prevent allergy until risk evaluation by a health professional. In conclusion, the present consensus statement provides recommendations regarding diagnosis, prevention and management of CMPA in infants and children in Turkey, and thus expected to guide physicians to optimize their approach to CMPA and decrease burden of the disease on infants and their caregivers.

Key words: cow's milk protein allergy, clinical practice, guidelines, diagnosis, treatment, prevention, Turkey. 
Food allergy is a reproducible specific immune response to the exposure to a given food ${ }^{1}$. Cow's milk protein allergy (CMPA) is a clinically abnormal reaction to cow's milk protein (CMP) via immune mechanisms triggered by milk protein ${ }^{2}$. According to the European Academy for Allergy and Clinical Immunology (EAACI) and the World Allergy Organization (WAO), a hypersensitivity reaction to cow's milk involving the immune system can be called as CMPA ${ }^{3}$. In this regard, involvement of immune system differentiates CMPA from non-allergic cow's milk intolerance (lactose intolerance) which occurs as a result of lactase deficiency without involvement of the immune system ${ }^{2,4}$.

CMP is the most common cause of food allergy in infants and young children aged younger than 3 years ${ }^{5}$. CMPA associated with gastrointestinal symptoms only can be observed in all age groups ${ }^{5}$. Based on the type of immune reaction responsible for development of CMPA, CMPA is categorized into immunoglobulin (Ig) $\mathrm{E}$ mediated, non-IgE mediated, or mixed CMPA ${ }^{5,6}$.

IgE-mediated CMPA manifests as phenotypical expression of atopy, with or without atopic eczema, allergic rhinitis and/or asthma in most children with CMPA, while non-IgE mediated reaction occurs in a subset of patients mainly with gastro-intestinal manifestations in response to cow's milk ingestion ${ }^{7}$.

Presence of sufficient awareness of the fact that prevention of CMPA is possible by following guidelines for the diagnosis and management of the condition is important given the considerable burden placed by the symptomatic manifestations of CMPA on both the infant and their parents ${ }^{8}$.

Without an appropriate diagnostic workup, a risk for both over and under-diagnosis and thus over and under-treatment has been considered likely in CMPA patients, which restricts the introduction of appropriate diet and maintenance of normal growth and development. For this reason, availability of evidence-based guidance seems critical to be able to manage the disease and to advise parents properly 5,9 .

Although evidence-based guidelines as well as consensus reports are available in the literature considering the diagnosis and management of CMPA $1,2,5,7,8,10-13$, there are no region- specific recommendations representing local experiences and challenges for the prevention, diagnosis, and treatment of CMPA in Turkey. Therefore, the present paper aims to provide a consensus statement on the diagnosis, treatment and follow-up of CMPA among infants and children in Turkey.

\section{Material and Methods}

An expert panel consisting of 4 pediatric gastroenterology and 2 pediatric allergy specialists from university hospitals met for two meetings to develop consensus opinion on the diagnosis, treatment and follow-up of CMPA in Turkey. The panel critically analyzed recommendations from international guidelines, review articles and published results of randomized control trials for diagnosis, treatment and follow-up of infant and childhood CMPA. Following consideration of the validity, clinical relevance, and applicability of the evidence for CMPA in the Turkey, the panel achieved agreement on a series of recommendations supported by scientific evidence and experts' clinical opinion.

\section{Epidemiology of CMPA}

Although no comparable international epidemiological data on CMPA prevalence exists because of different methods and geographical regions in clinical evaluation ${ }^{7}$, data from cohort studies and meta-analyses revealed an overall $1.9 \%$ to $4.9 \%$ prevalence of CMPA among children with a peak in prevalence $(2-3 \%)$ in the first year of life and prevalence of $<1 \%$ in children aged $\geq 6$ years $4,7,14-17$. Parents notice CMPA in their children much more frequently than can be confirmed by appropriate tests, and symptoms suggesting adverse reactions to CMP occur in a $5 \%$ to $15 \%$ of infants exceeding the true estimates of CMPA prevalence ${ }^{18}$. Therefore, an accurate diagnosis of CMPA is important to prevent infants from being put on inappropriate elimination diets ${ }^{13,19}$.

Prognosis of CMPA in infancy is good; remission rate is reported to be up to 85$90 \%$ at 3 years with better prognosis in cases of gastrointestinal symptoms ${ }^{19}$.

\section{Clinical manifestations of CMPA}

CMPA can produce a range of symptoms varying in intensity in infants including "immediate" 
(early; from minutes after allergen ingestion up to 2 hours) reactions and "delayed" (late; up to 48 hours to a few weeks following ingestion) reactions ${ }^{5,20}$.

As summarized in Table $\mathrm{I}^{20}$, given the clinical presentations typical for each type of immune reaction, CMPA is categorized into IgE-mediated, non-IgE mediated or mixed type CMPA ${ }^{5,20}$. Symptoms and signs of CMPA may be related to the skin, the gastrointestinal tract and the respiratory tract ${ }^{5}, 20$. They are variable, mostly nonspecific including oral and perioral swelling, dysphagia, food impaction (e.g. impaired esophageal motility), regurgitation, vomiting, diarrhea with or without malabsorption or protein loss due to enteropathy, persistent constipation often with perianal dermatitis and/or fissure, rectal bleeding, anorexia, food refusal, failure to thrive, abdominal pain, and severe colic $^{5,20}$.

IgE-mediated CMPA has atopic manifestations such as urticaria, angioedema, vomiting, diarrhea, eczema, rhinitis, and anaphylaxis ${ }^{5}$. Non-IgE mediated CMPA encompasses food proteininduced enterocolitis syndrome (FPIES), food protein-induced allergic proctocolitis (FPIAP) and food protein-induced enteropathy ${ }^{2,21}$. FPIES is relatively uncommon and manifests usually in infants as profuse repetitive vomiting (onset one to three hours after ingestion) and diarrhea (onset 5-10 hours) that may be accompanied by lethargy, acute and severe edema, shock and moderate failure to thrive, generally without acute respiratory and skin manifestations 2,21 . The symptoms mimic sepsis, metabolic disease or acute abdominal problems, which lead to under-diagnosis of this condition. FPIAP, on the contrary, is a benign transient condition, which typically starts in the first few months of life while being exclusively breast fed, with blood-streaked stools and occasionally mild diarrhea with no emesis or signs of shock or failure to thrive in well-appearing infants without growth retardation and considered as one of the major causes of colitis under age one year ${ }^{2,21}$. Enteropathy due to CMPA is associated with intermittent vomiting, chronic diarrhea, steatorrhea, moderate edema due to hypoalbuminemia, poor weight gain and lack of signs of shock ${ }^{21}$. Mixed type CMPA may present as eosinophilic esophagitis, eosinophilic gastroenteritis and eosinophilic colitis, and can manifest at any age with a male predominance and symptoms ranging from chronic abdominal pain, nausea, vomiting, dysphagia, food impaction, diarrhea to weight loss, anemia and malabsorption depending on the extent of bowel involvement ${ }^{1,21,22}$.

While some symptoms such as angioedema and atopic eczema are more likely to be seen in CMP-specific IgE positive children; the same symptoms may also appear in CMP IgE-negative patients, particularly those having gastrointestinal manifestations such as allergic proctocolitis ${ }^{5,23}$.

\section{Diagnosis of CMPA}

Figure 1 illustrates an algorithm for infants and children with symptoms suggestive of $\mathrm{CMPA}^{20}$. If CMPA is suspected, a differential diagnosis is needed including family history and physical examination as the initial step. If any of the findings presented in Table I occurs, the second step is conducting a differential diagnosis with or without laboratory evaluation, and when manifestations cannot be associated with any other cause, CMPA may be thought as a potential diagnosis ${ }^{5}$. CMPA diagnosis should be based on symptomatic evaluation and diagnostic elimination diet as followed by an oral challenge test after disappearance of symptoms and confirmation of CMPA diagnosis in re-appearance of symptoms $5,8,20$.

If CMPA is likely with relevant symptoms, elimination of CMP in the child's and/or breastfeeding mother's diet should be tried for limited time to confirm the diagnosis. The duration of a diagnostic elimination diet should be decided according to clinical manifestation; usually for 3 to 5 days if immediate clinical reactions, and 1 to 2 weeks if delayed clinical reactions are observed, while 2 to 4 weeks on a CMPfree diet before evaluation may be necessary in patients with gastrointestinal reactions ${ }^{5}$. If no improvement in symptoms within these timelines is achieved, then CMPA diagnosis is not likely; though, multiple food allergies and other diseases should be considered.

For diagnostic elimination in breast-fed infants, breast-feeding is continued while avoiding all milk and milk products like cheese, yogurt and butter from the maternal diet in accordance with qualified dietary counseling. If symptoms continue on breast milk despite a strict maternal 


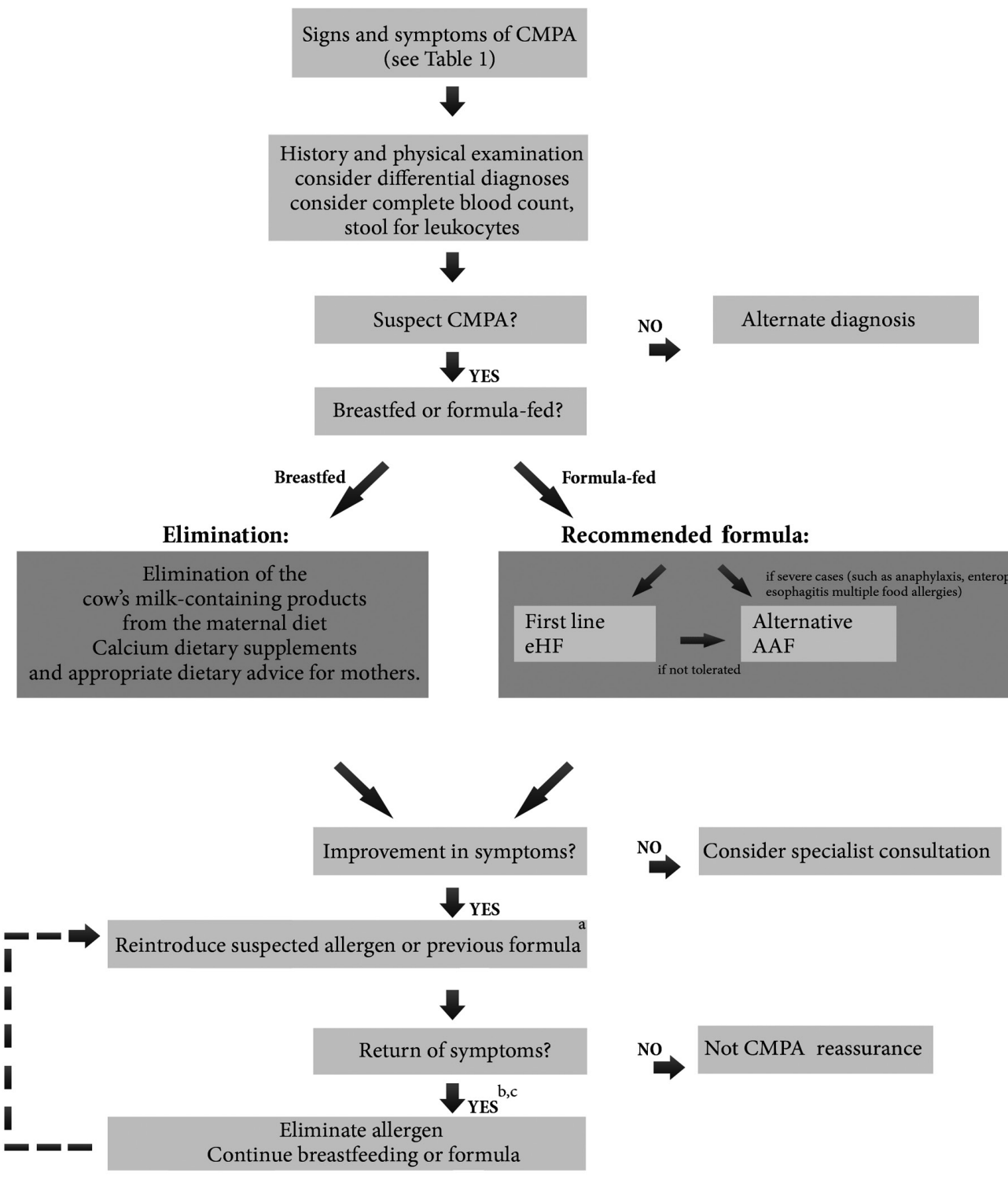

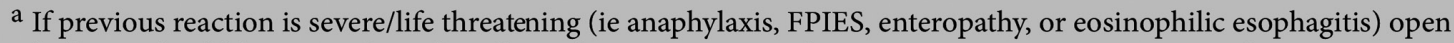
challenge should be omitted, until performed in an experienced center or reaction is consistent and reproducible (occurred more than one occasion with similar clinical presentation) can be postponed.

${ }^{\mathrm{b}}$ Confirmed CMPA diagnosis;

- The elimination diet should be maintained for at least 4-6 months or until 9 to 12 months of age

- Patient with severe immediate IgE-mediated reactions may remain on the elimination diet for 12 or even 18 months before they are re-challenged after repeated testing for spesific IgE.

${ }^{c}$ Re-challenge after maintaining an elimination diet for at least 4-6 months in case of spesific IgE negativity/mild symptoms and at least 12 months in case of high-Ig E positivity/severe reactions.

When challenge is positive, elimination diet should be continued for another 6 to 12 months. Introduction of supplementary foods should not be delayed and should be made one by one in small amounts after the infant is at least 17 weeks of age.
}

Fig. 1. An algorithm for the diagnosis and treatment of cow's-milk protein allergy Adapted from Brill H. Approach to milk protein allergy in infants. Can Fam Physician. 2008 Sep; 54(9): 1258-126420. 
Table I. Clinical Presentations of Cow's Milk Protein Allergy Ordered by Organ System and Type of Immune Reaction ${ }^{20}$.

\begin{tabular}{l} 
Reaction type \\
\hline IgE mediated \\
Respiratorya
\end{tabular}

Cutaneous

Gastrointestinal

Non-IgE mediated

Respiratory

Cutaneous

Gastrointestinal

Mixed

Cutaneous

Gastrointestinal

Other

Unclassified (rare) ${ }^{\mathrm{b}}$
Presentation

Rhinoconjunctivitis

Asthma (wheeze, cough)

Laryngeal edema

Otitis media with effusion ${ }^{b}$

Atopic dermatitis

Urticaria

Angioedema

Anaphylaxis

Oral allergy syndrome

Nausea and vomiting

Diarrhea

Pulmonary hemosiderosis (Heiner syndrome)

Contact rash

Atopic dermatitis

Regurgitation

Vomiting

Chronic diarrhea

Protein-losing enteropathy

Blood in stool

Colic

Constipation

Food refusal

Food protein-induced enterocolitis syndrome (FPIES)

Food protein-induced allergic proctocolitis (FPIAP)

Food protein-induced enteropathy

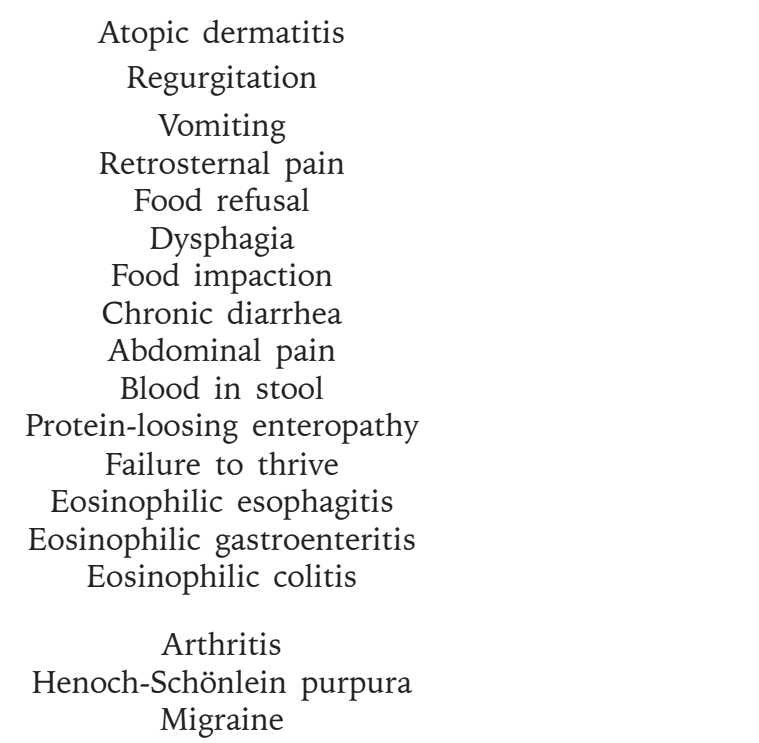

${ }^{a}$ Always associated with other organ system involvement, ${ }^{\mathrm{b}}$ These presentations are still on debate

Adapted from Brill H. Approach to milk protein allergy in infants. Can Fam Physician. 2008 Sep; 54(9): 1258-1264 20. 
CMP-free diet, other highly allergenic foods should further be eliminated from the mother's diet or a therapeutic formula is recommended instead of breast milk $\mathrm{k}^{5,20,24}$.

In non-breast-fed infants, cow's-milk and CMP containing formula and supplementary foods or other unmodified animal milk proteins (e.g. goat's milk, sheep's milk) should be strictly forbidden ${ }^{25,26}$ during the diagnostic elimination period. If the first feeds with cow's-milk-based formula or supplementary food in a breast-fed infant causes symptoms, formula should be changed and the elimination should be made in the infant's, not in the mother's diet. In formula-fed infants the first elimination diet is an extensively hydrolyzed infant formula (eHF) with proven efficacy in $\mathrm{CMPA}^{5,25}$. If no improvement is seen within 2-4 weeks, the cause of the allergic reaction may be the remaining peptides in the eHF, particularly if the infant has sensitization for multiple foods. In such patients, it is recommended to try amino acid formula (AAF) before CMPA is excluded among the causes of the symptoms ${ }^{5}$. Furthermore, in in case of extremely severe or life-threatening symptoms, the first choice should be an AAF.

When significant improvement on the diagnostic elimination is documented, a standardized oral challenge test should be performed to confirm the diagnosis of CMPA, under medical supervision in inpatient or outpatient settings. If previous reaction is severe/life threatening (i.e. anaphylaxis, FPIES, enteropathy, or eosinophilic esophagitis) open challenge should be omitted until performed in an experienced center or if reaction is consistent and reproducible (occurred more than one occasion with similar clinical presentation) can be postponed.

Open challenge in an IgE mediated reaction should be always conducted with caution under medical supervision at day 1 with a dose escalated fashion as depicted elsewhere ${ }^{1,2,4,5,7}$. If no reaction is observed at day 1 , the child should continue taking a daily dose of the food corresponding to the average age-appropriate portion size over the next days (3-14 days).

This approach provides documenting signs and symptoms, milk volume arousing the symptoms in order to plan symptomatic treatment as needed $^{5}$. If feeding regular cow's-milk for 2-weeks elicits no symptoms, CMPA is excluded and a CMP may be reintroduced into maternal $\operatorname{diet}^{5}$. If symptoms appear in response to an open challenge test, double blind placebo controlled food challenge (DBPCFC) which is the reference standard and the most specific test for diagnosing CMPA, albeit time-consuming and expensive, is recommended if symptoms are uncertain or questionable or in cases with moderate to severe eczema. This approach is advised to minimize bias by the patients, caregivers, and physicians ${ }^{5}$.

Considering other tests in CMPA diagnostic work-up, specific IgE testing should be tried to confirm IgE-mediated allergy diagnosis only presenting with acute and objective symptoms such as angioedema, acute urticaria, wheezing, stridor, and anaphylactic reactions (following ingesting dairy products) $7,27,28$. Prick tests can be used for diagnosis, but positive results are not necessarily predictive of the outcome of challenge tests $7,27,28$. In cases of nonspecific symptoms such as frequent regurgitation and constipation or symptoms caused by nonIgE-mediated reactions such as bloody stools, allergy tests are not cost-effective as primary diagnostic tools for CMPA 5 .

The experts agreed that while being commonly applied in the first 6 months of life, specific IgE test is not a very reliable test in this period due to already low levels of IgE. Therefore the importance of open challenge test is emphasized especially in the first 6 months of life given that specific IgE tests could not be useful in this age group. Also, given that detection of IgG or IgG subclass antibodies against CMP does not have diagnostic value in CMPA $^{29}$, experts indicated that IgG mediated food allergy tests should not be performed in the diagnosis of CMPA, in accordance with recommendations ${ }^{1}$. Experts also indicated that in patients with significant and persistent gastrointestinal symptoms due to unexplained causes, failure to thrive, or iron deficiency anemia, use of endoscopies with multiple biopsies are recommended; but macroscopic lesions, mucosal atrophy and eosinophilic infiltrates in histological samples are not sensitive/specific for $\mathrm{CMPA}^{30}$. Experts also emphasized that colonoscopy is not indicated for the diagnosis of FPIAP. Notably, given that many children with CMPA are misdiagnosed as lactose intolerance or gastrointestinal amebiasis 
(as in the cases of FPIAP) and followed up without being treated for CMPA in Turkey, experts emphasized the importance of open challenge test in differential diagnosis of nonspecific symptoms.

\section{Treatment of CMPA}

The safest strategy in managing CMPA is to strictly avoid from CMP. The decision of using a substitute formula and choosing the best formula to fulfill nutritional requirements of the children with CMPA should be done mostly based on the age of the patient and the history of other food allergies ${ }^{5}$. The consensus recommendations for CMPA management are presented in Figure 120 .

For exclusively breastfed infants, diagnostic elimination involves elimination of the products containing cow's milk including cheese, yogurt and butter from the maternal diet. Breastfeeding mothers who eliminate cow's milk products from their diet for long periods should take calcium supplements and take dietary counselling to avoid nutritional deficiencies ${ }^{5}$.

Cow's milk-based formula and any complementary food containing CMP should be avoided in exclusively breastfed infants. When symptoms of allergy occur in formula-fed infants, either exclusively or as a supplement to breastfeeding, they should be given a therapeutic formula that has clinically proven reduced allergenicity and high tolerability ${ }^{31,32}$. Extensively hydrolyzed formula (eHF; casein or whey) and AAF are the two such alternatives recommended for formula feeding among infants with CMPA $^{7,19,31}$.

eHFs are indicated in treatment and in prevention of CMPA and tolerated by the majority of infants and children with $\mathrm{CMPA}^{5,19}$. AAF is developed to overcome the hypersensitivity against residual proteins in eHF, particularly in cases with severe enteropathy or with multiple food allergies ${ }^{5}$. For that reason, AAF may be considered only in infants with severe reactions such as anaphylaxis, enteropathy, eosinophilic esophagitis and food protein induced enterocolitis along with cases of multiple system involvement, multiple food allergies and intolerance to $\mathrm{eHF}^{5,8,33}$. While soy-based formulae are associated with lower allergenicity than cow's milk-based formulae 34,35 , concerns about the isoflavone (phytoestrogen) content have been raised ${ }^{36}$.
Accordingly, ESPGHAN and American Academy of Pediatrics (AAP) consider use of eHF and AAF for the dietary treatment of infants with CMPA as the first option if eHF is not better tolerated than soy protein-based formulae ${ }^{35,37}$. Partially hydrolyzed formulae (pHF) based on CMP, other mammalian proteins, and milk from other mammalians are not recommended $8,25,26,38$.

In infants with documented CMPA and exclusively breast-fed and formula-fed, weaning food should be free of CMP until the development of tolerance is confirmed by oral challenge tests. Introduction of supplementary foods should not be delayed while should be made one by one in small amounts and only after the infant is at least 17 weeks of age, preferably while the mother is still breastfeeding $5,39,40$.

Among children with CMPA on elimination diet beyond the first 12 months of age, dietary supervision by a health professional specialized or trained in pediatric nutrition is recommended to decide about sufficient amounts of nutrients, proteins, calcium, vitamin $\mathrm{D}$, and vitamin $\mathrm{A}$ in the diet and the need for a therapeutic formula or supplements to achieve a normal growth for age ${ }^{41}$.

\section{Evaluation by re-challenge}

While CMPA has traditionally been considered to resolve by 1 to 2 years of age, evidences to define an optimal interval before reevaluation are not sufficient ${ }^{5,8,20}$. Age, severity of a child's symptoms, and positivity of specific IgE for CMP are amongst the factors that determine the duration of exclusion 5 .

Following confirmation of CMPA diagnosis, maintenance on an elimination diet by a therapeutic formula has been recommended using for at least 6 months or until 9 to 12 months of age. Infants and children with severe immediate IgE-mediated reactions may stay on the elimination diet longer (12 or even 18 months) before re-challenge following the repeat tests specific for $\operatorname{IgE}^{5}$. On the basis of its correlation with persistence of allergy, high specific IgE levels are considered to be a useful predictor of patient outcome ${ }^{42}$, while low levels of specific IgE antibodies were shown to be associated with faster gain of milk tolerance among CMPA patients ${ }^{20}$. Hence, in specific IgE negative cases with mild symptoms, 
conventional approach considers a re-challenge with cow's milk after a therapeutic diet for at least 4-6 months, while up to at least 12 months in case of high-Ig E positivity or severe reactions, to avoid unnecessary prolongation of restrictive diet and the likelihood of improper growth ${ }^{1,5}$.

Re-challenge may lead to severe reaction particularly if the patient had a previous severe/ life threatening reaction history, therefore a dose-titrated challenge should be performed in experienced clinic under close monitoring.

If a challenge gives positive results, usually the elimination diet is continued for 6 to 12 months. If it is negative, then the child is fully re-exposed to cow's milk. If CMP challenge test is negative, the infant may be safely moved to a standard cow's milk formula (CMF). If a child on AAF can tolerate eHF challenge, it is safe to move the infant to an eHF. If a response to either a CMP or eHF challenge test is observed, the infant should be kept on the therapeutic formula that resolved the symptomatic manifestations of CMPA ${ }^{5,8,43}$.

The prognosis of infancy and young childhood CMPA is good. Tolerance develops in up to $50 \%$ of the affected children by the age of 1 year, up to $85 \%$ by the age of 3 years, and up to $90 \%$ has become tolerant by the age of 6 years $^{5,17}$.

\section{Prevention of CMPA}

The best approach to prevent allergy is exclusive breastfeeding for 4-6 months (17-27 weeks) ${ }^{8}$ that has been shown to have significant protective effect against atopic dermatitis in comparison to conventional $\mathrm{CMF}^{44,45}$.

No benefit of modulation of maternal diet has been shown in decreasing incidence of allergy 46,47 along with the likelihood of an unbalanced maternal diet to negatively affect one or both of fetal and maternal nutrition ${ }^{8,24}$. Accordingly, recent guidelines consistently recommend not modifying maternal diet during pregnancy or lactation to prevent $\mathrm{CMPA}^{2,8,10}$.

At-risk infants should be identified by family history for atopic conditions such as CMPA, food allergy, atopic dermatitis, asthma, allergic rhinitis, and should receive a prevention diet if at risk of allergy and not exclusively breastfed. Use of hydrolyzed formulae has been recommended by the guidelines in at-risk infants who are not breastfed for the prevention of CMPA until their risk has been assessed by healthcare personnel ${ }^{2,8,10}$.

pHF has been produced to minimize sensitizing epitopes of milk proteins, by keeping peptides in sufficient size and immunogenicity to induce oral tolerance. Thus containing larger peptides than eHF, they are not suitable in treatment of $\mathrm{CMPA}^{19,48}$. eHF and AAF remove allergenicity, but the loss of immunogenicity to prevent CMPA also keeps the immune system from developing tolerance to milk proteins ${ }^{48}$. Therefore, commonly pHF is used to prevent allergy ${ }^{19}$. Efficacy of using both pHF and eHF were shown in the prevention of allergy in at high risk infants ${ }^{44,49,50}$, while AAF is not recommended in prevention of $\mathrm{CMPA}^{8}$.

Hence experts agreed that it is difficult to assess allergy in neonates, and if exclusive breastfeeding is impossible, hydrolyzed formula (pHF or eHF) offers advantages in preventing cow's milk allergy until their risk has been assessed by a healthcare professional ${ }^{8}$.

There is no evidence confirming benefit from delayed introduction of solid even potentially allergenic foods beyond the age of 4-6 months to protect from allergy 5,39 . Experts agreed that supplementary foods should be introduced one at a time in small quantities, preferably while the mother is still breastfeeding but not before the infant is at least 17 weeks of age in accordance with ESPGHAN guidelines ${ }^{5}$.

Probiotic supplementation of mothers during pregnancy and lactation has been indicated to be likely to prevent early infant atopy, and supplementation of eHF with prebiotics has been considered likely to decrease the occurrence allergic manifestations, such as atopic dermatitis, recurrent wheezing, and allergic urticaria in infancy 51,52 . However, further evidence is required to recommend prebiotics safely in order to reduce atopic dermatitis incidence in routine practice ${ }^{8,53}$.

\section{Conclusion}

The present consensus statement provides recommendations for the diagnosis, prevention and management of suspected CMPA in infants and children in Turkey, based on evidencebased guidelines, literature data and expert clinical experience and in accordance with socioeconomic characteristics and current healthcare policies specific to our country. 
Diagnosis: Upon the experts' agreement, there is need for a differential diagnosis including starting from family history and a physical examination if CMPA is suspected. CMPA diagnosis should be based on symptomatic evaluation and diagnostic elimination diet as followed by an open challenge test after disappearance of symptoms except in those with severe or consistent allergy history and confirmation of CMPA diagnosis in reappearance of symptoms. Duration of diagnostic elimination ranges from 3 to 5 days in case of immediate clinical reactions, to 1 to 2 weeks if clinical reactions are delayed, while 2 to 4 weeks on a CMP-free diet before evaluation may be necessary in patients with gastrointestinal reactions. Although, the golden standard and the most specific diagnostic test for CMPA is DBPCFC; it is time-consuming and expensive and not a feasible diagnostic option in daily clinical practice in majority of centers across Turkey. Therefore, experts considered use of diagnostic algorithm provided in ESPGHAN guidelines to be appropriate in Turkey, with special emphasis on the contribution of open challenge test in providing accurate diagnosis and thereby limiting the likelihood of overtreatment or under-treatment ${ }^{5}$. Specific IgE tests may be considered in special circumstances to support diagnosis and resolution, whereas neither endoscopy nor IgG analysis has a role in CMPA diagnosis and endoscopic investigation can only be useful in the differential diagnosis in certain cases.

Treatment: For breastfed infants, diagnostic elimination is defined as eliminating cow's milk-containing products from the mother's diet, calcium supplementation and dietary advice in order to avoid nutritional deficiencies in elimination diet lasting long. If the infant is not exclusively breastfed, not only cow's milk-based formula, but also complementary foods containing CMP should be avoided. Experts recommend first line treatment with eHF in infants not exclusively breastfed, while the use of AAF is considered in infants with severe reactions such as anaphylaxis, enteropathy, eosinophilic esophagitis and food protein induced enterocolitis along with cases of multiple system involvement, multiple food allergies and intolerance to $\mathrm{eHF}^{5,8,33}$.

Infants with a confirmed diagnosis of CMPA should maintained an elimination diet with a therapeutic formula at least for 4-6 months or until the age of 9 to 12 months, while both infants and children who have severe immediate IgE-mediated reactions may receive the elimination diet longer (12 or even 18 months) before the re-challenged following the repeat IgE-specific testing. Conventional approach considers a cow's milk re-challenge after a therapeutic diet for at least 4-6 months in case of specific IgE negativity and mild symptoms, while up to at least 12 months in case of high-Ig E positivity or severe reactions, to avoid unnecessary prolongation of restrictive diet and the likelihood of improper growth ${ }^{1,5}$. If a challenge produces positive response, the elimination diet is usually continued for another 6 to 12 months. If it is negative, then the child is re-exposed to cow's milk containing diet ${ }^{5}$.

Introduction of supplementary foods should not be delayed and should be made one by one in small amounts after the infant is at least 17 weeks of age, preferably while the mother is still breastfeeding $5,39,40$.

Prevention: The best method to prevent infant allergy is exclusive breastfeeding for 4-6 months. There is no evidence showing the benefit of modifying maternal diet during pregnancy or lactation, delaying solid and potentially allergic foods beyond 4-6 months in at-risk infants. When breastfeeding exclusively is impossible, all at-risk infants should receive a hydrolyzed formula (pHF or eHF) that appears to be advantageous in preventing allergic conditions including cow's milk allergy until a risk assessment by a healthcare professional ${ }^{8}$.

Given the limited number of studies concerning epidemiology and practice patterns in CMPA in Turkey, the main limitation of the current statement seems to be the fact that present recommendations are dependent on the expert clinical opinion of the panel members rather than data on the prevalence of CMPA or the efficacy of CMPA treatment strategies.

In conclusion, the present consensus statement is the first to provide recommendations for the diagnosis, prevention and management of CMPA in infants and children in Turkey. These recommendations should assist healthcare practitioners to optimize their approaches in managing CMPA and reducing the burden of disease on the infants and the family. Given the lack of reliable objective diagnostic tools 
and thus strict diagnostic criteria to minimize misdiagnosis of CMPA, clinical assessment via elimination and challenge tests remains a fundamental for the accurate diagnosis of CMP. Hence, there is a need for studies addressing epidemiology of CMPA and practice patterns in the management of CMPA in Turkey along with awareness of physicians and parents about CMPA.

\section{Acknowledgments}

We give thanks to Cagla Ayhan, MD and Prof. Sule Oktay, MD, PhD. from KAPPA Consultancy Training Research Ltd, Istanbul who provided editorial support and Mehmet Berktas, MD, MICR from KAPPA Consultancy Training Research Ltd, Istanbul who created patient management algorithm and was responsible for management of the project.

\section{REFERENCES}

1. Boyce JA, Assa'ad A, Burks AW, et al. Guidelines for the diagnosis and management of food allergy in the United States: report of the NIAID sponsored expert panel. J Allergy Clin Immunol 2010; 126: S1-58.

2. Boyce JA, Assa'ad A, Burks AW, et al. NIAID-Sponsored Expert Panel. Guidelines for the Diagnosis and Management of Food Allergy in the United States: Summary of the NIAID-Sponsored Expert Panel Report. J Allergy Clin Immunol 2010; 126: 1105-1118.

3. Johansson SG, Bieber T, Dahl R, et al. Revised nomenclature for allergy for global use: report of the nomenclature review committee of the world allergy organization, October 2003. J Allergy Clin Immunol 2004; 113: 832-836.

4. Venter C, Brown T, Shah N, Walsh J, Fox AT. Diagnosis and management of non-IgE-mediated cow's milk allergy in infancy - a UK primary care practical guide. Clin Transl Allergy 2013; 3: 23.

5. Koletzko S, Niggemann B, Arato A, et al. European Society of Pediatric Gastroenterology, Hepatology, and Nutrition. Diagnostic approach and management of cow's-milk protein allergy in infants and children: ESPGHAN GI Committee practical guidelines. J Pediatr Gastroenterol Nutr 2012; 55: 221-229.

6. Sicherer SH, Noone SA, Koerner CB, Christie L, Burks AW, Sampson HA. Hypoallergenicity and efficacy of an amino acid-based formula in children with cows' milk and multiple food hypersensitivities. J Pediatr 2001; 138: 688-693.

7. Fiocchi A, Brozek J, Schünemann $\mathrm{H}$, et al. World Allergy Organization (WAO) Diagnosis and Rationale for Action against Cow's Milk Allergy (DRACMA) Guidelines. World Allergy Organ J 2010; 3: 57-161.

8. Vandenplas Y, Abuabat A, Al-Hammadi S, et al. Middle East Consensus Statement on the Prevention, Diagnosis, and Management of Cow's Milk Protein Allergy. Pediatr Gastroenterol Hepatol Nutr 2014; 17: 61-73.
9. Eggesbo M, Botten G, Halvorsen R, Magnus P. The prevalence of CMA/CMPI in young children: the validity of parentally perceived reactions in a population-based study. Allergy 2001; 56: 393-402.

10. Greer FR, Sicherer SH, Burks AW; American Academy of Pediatrics Committee on Nutrition; American Academy of Pediatrics Section on Allergy and Immunology. Effects of early nutritional interventions on the development of atopic disease in infants and children: the role of maternal dietary restriction, breastfeeding, timing of introduction of complementary foods, and hydrolyzed formulas. Pediatrics 2008; 121: 183-191.

11. Kemp AS, Hill DJ, Allen KJ, et al. Guidelines for the use of infant formulae to treat cow's milk protein allergy: an Australian consensus panel opinion. Med J Aust 2008; 188: 109-112.

12. Allen KJ, Davidson GP, Day AS, et al. Management of cow's milk protein allergy in infants and young children: an expert panel perspective. J Paediatr Child Health 2009; 45: 481-486.

13. Vandenplas Y, Brueton M, Dupont C. Guidelines for the diagnosis and management of cow's milk protein allergy in infants. Arch Dis Child 2007; 92: 902-908.

14. Venter C, Pereira B, Voigt K, et al. Prevalence and cumulative incidence of food hypersensitivity in the first 3 years of life. Allergy 2008, 63: 354-359.

15. Sicherer SH. Epidemiology of food allergy. J Allergy Clin Immunol 2011; 127: 594-602.

16. Rona RJ, Keil T, Summers C, et al. The prevalence of food allergy: a meta-analysis. J Allergy Clin Immunol 2007; 120: 638-646.

17. Host A, Halken S, Jacobsen HP, Christensen AE, Herskind AM, Plesner K. Clinical course of cow's milk protein allergy/intolerance and atopic diseases in childhood. Pediatr Allergy Immunol 2002; 13: 23-28.

18. Host A. Frequency of cow's milk allergy in childhood. Ann Allergy Immunol 2002; 89: 33-37.

19. Vandenplas Y, De Greef E, Devreker T. Treatment of cow's milk protein allergy. Pediatr Gastroenterol Hepatol Nutr 2014; 7: 1-5.

20. Brill H. Approach to milk protein allergy in infants. Can Fam Physician 2008; 54: 1258-1264.

21. Assa'ad AH, Putnam PE, Collins MH, et al. Pediatric patients with eosinophilic esophagitis: an 8-year followup. J Allergy Clin Immunol 2007; 119: 731-738.

22. Talley NJ, Shorter RG, Phillips SF, Zinsmeister AR. Eosinophilic gastroenteritis: a clinicopathological study of patients with disease of the mucosa, muscle layer, and subserosal tissues. Gut 1990; 31: 54-58.

23. Shek LP, Bardina L, Castro R, Sampson HA, Beyer K. Humoral and cellular responses to cow milk proteins in patients with milk-induced IgE-mediated and nonIgE-mediated disorders. Allergy 2005; 60: 912-919.

24. Kramer MS, Kakuma R. Maternal dietary antigen avoidance during pregnancy or lactation, or both, for preventing or treating atopic disease in the child. Cochrane Database Syst Rev 2006; 3: CD000133.

25. Host A, Koletzko B, Dreborg S, et al. Dietary products used in infants for treatment and prevention of food 
allergy. Joint statement of the European Society for Paediatric Allergology and Clinical Immunology (ESPACI) Committee on Hypoallergenic Formulae and the European Society for Paediatric Gastroenterology, Hepatology and Nutrition (ESPGHAN) Committee on Nutrition. Arch Dis Child 1999; 81: 80-84.

26. Jarvinen KM, Chatchatee P. Mammalian milk allergy: clinical suspicion, cross-reactivities and diagnosis. Curr Opin Allergy Clin Immunol 2009; 9: 251-258.

27. Celik-Bilgili S, Mehl A, Verstege A, et al. The predictive value of specific immunoglobulin E levels in serum for the outcome of oral food challenges. Clin Exp Allergy 2005; 35: 268-273.

28. Verstege A, Mehl A, Rolinck-Werninghaus C, et al. The predictive value of the skin prick test weal size for the outcome of oral food challenges. Clin Exp Allergy 2005; 35: 1220-1226.

29. Stapel SO, Asero R, Ballmer-Weber BK, et al.; EAACI Task Force. Testing for IgG4 against foods is not recommended as a diagnostic tool: EAACI task force report. Allergy 2008; 63: 793-796.

30. Nielsen RG, Fenger C, Bindslev-Jensen C, Husby S. Eosinophilia in the upper gastrointestinal tract is not a characteristic feature in cow's milk sensitive gastro-oesophageal reflux disease. Measurement by two methodologies. J Clin Pathol 2006; 59: 89-94.

31. American Academy of Pediatrics. Committee on Nutrition. Hypoallergenic infant formulas. Pediatrics 2000; 106: 346-349.

32. Giampietro PG, Kjellman NI, Oldaeus G, WoutersWesseling W, Businco L. Hypoallergenicity of an extensively hydrolyzed whey formula. Pediatr Allergy Immunol 2001;12: 83-86.

33. Isolauri E, Sutas Y, Makinen-Kiljunen S, Oja SS, Isosomppi R, Turjanmaa K. Efficacy and safety of hydrolyzed cow milk and amino acid-derived formulas in infants with cow milk allergy. J Pediatr 1995; 127: 550-557.

34. Halpern SR, Sellars WA, Johnson RB, Anderson DW, Saperstein S, Reisch JS. Development of childhood allergy in infants fed breast, soy, or cow milk. J Allergy Clin Immunol 1973; 51: 139-151.

35. Bhatia J, Greer F; American Academy of Pediatrics Committee on Nutrition. Use of soy protein-based formulas in infant feeding. Pediatrics 2008; 121: 10621068.

36. Vandenplas Y, Castrellon PG, Rivas R, et al. Safety of soya-based infant formulas in children. Br J Nutr 2014; 111: 1340-1360.

37. Agostoni C, Axelsson I, Goulet O, et al; ESPGHAN Committee on Nutrition. Soy protein infant formulae and follow-on formulae: a commentary by the ESPGHAN Committee on Nutrition. J Pediatr Gastroenterol Nutr 2006; 42: 352-361.

38. Ehlayel M, Bener A, Abu Hazeima K, Al-Mesaifri F. Camel milk is a safer choice than goat milk for feeding children with cow milk allergy. ISRN Allergy 2011; 2011: 391641.

39. Agostoni C, Decsi T, Fewtrell M, et al. ESPGHAN Committee on Nutrition. Complementary feeding: a commentary by the ESPGHAN Committee on Nutrition. J Pediatr Gastroenterol Nutr 2008; 46: 99-110.

40. Agostoni C, Braegger C, Decsi T, et al. ESPGHAN Committee on Nutrition. Breast-feeding: a commentary by the ESPGHAN Committee on Nutrition. J Pediatr Gastroenterol Nutr 2009; 49: 112-125.

41. Laitinen K, Kalliomaki M, Poussa T, Lagström H, Isolauri E. Evaluation of diet and growth in children with and without atopic eczema: follow-up study from birth to 4 years. Br J Nutr 2005; 94: 565-574.

42. Skripak JM, Matsui EC, Mudd K, Wood RA. The natural history of IgE-mediated cow's milk allergy. J Allergy Clin Immunol 2007; 120: 1172-1177.

43. Ludman S, Shah N, Fox AT. Managing cows' milk allergy in children. BMJ 2013; 347: f5424.

44. von Berg A, Filipiak-Pittroff B, Krämer U, et al. GINIplus study group. Allergies in high-risk schoolchildren after early intervention with cow's milk protein hydrolysates: 10-year results from the German Infant Nutritional Intervention (GINI) study. J Allergy Clin Immunol 2013; 131: 1565-1573.

45. Yang YW, Tsai CL, Lu CY. Exclusive breastfeeding and incident atopic dermatitis in childhood: a systematic review and meta-analysis of prospective cohort studies. Br J Dermatol 2009; 161: 373-383.

46. Fälth-Magnusson K, Kjellman NI. Allergy prevention by maternal elimination diet during late pregnancy-a 5 -year follow-up of a randomized study. J Allergy Clin Immunol 1992; 89: 709-713.

47. Lilja G, Dannaeus A, Foucard T, Graff-Lonnevig V, Johansson SG, Oman H. Effects of maternal diet during late pregnancy and lactation on the development of IgE and egg- and milk-specific IgE and IgG antibodies in infants. Clin Exp Allergy 1991; 21: 195-202.

48. Crittenden RG, Bennett LE. Cow's milk allergy: a complex disorder. J Am Coll Nutr 2005; 24: 582S-591S.

49. Marini A, Agosti M, Motta G, Mosca F. Effects of a dietary and environmental prevention programme on the incidence of allergic symptoms in high atopic risk infants: three years' follow-up. Acta Paediatr Suppl 1996; 414: 1-21.

50. Vandenplas Y, Hauser B, Van den Borre C, et al. The long-term effect of a partial whey hydrolysate formula on the prophylaxis of atopic disease. Eur J Pediatr 1995; 154: 488-494.

51. Kalliomäki M, Salminen S, Poussa T, Arvilommi H, Isolauri E. Probiotics and prevention of atopic disease: 4-year follow-up of a randomised placebo-controlled trial. Lancet 2003; 361: 1869-1871.

52. Arslanoglu S, Moro GE, Schmitt J, Tandoi L, Rizzardi $\mathrm{S}$, Boehm G. Early dietary intervention with a mixture of prebiotic oligosaccharides reduces the incidence of allergic manifestations and infections during the first two years of life. J Nutr 2008; 138: 1091-1095.

53. Osborn DA, Sinn JK. Prebiotics in infants for prevention of allergy. Cochrane Database Syst Rev 2013; 3: CD006474. 